\title{
INFLUENCE OF SURFACE TENSION EFFECTS ON SOLIDIFICATION OF ALLOYS IN SPACE AND ON GROUND
}

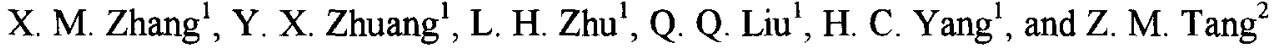 \\ 'Institute of Metal Research, CAS, Shenyang 110015, China \\ ${ }^{2}$ Institute of Mechanics, Microgravity Division, CAS, Beijing 100080, China
}

\begin{abstract}
Solidification experiments of $\mathrm{Al}-\mathrm{Al}_{3} \mathrm{Ni}$ and $\mathrm{Al}-\mathrm{Bi}$ alloys were carried out in space on board a Chinese recoverable satellite. An obvious double vortical radiant structure of $\mathrm{Al}-\mathrm{Al}_{3} \mathrm{Ni}$ eutectic and a homogeneous microstructure of $\mathrm{Al}-\mathrm{Bi}$ monotectic were obtained. Combined fluid physics and metallography, the effect of surface tension gradient driven convection on the formation of radiant eutectic structure and the Marangoni migration of second-phase droplets in the molten alloy were analyzed.
\end{abstract}

() 1999 COSPAR. Published by Elsevier Science Ltd.

\section{INTRODUCTION}

Based on results from experiments in space, it was found that the convection driven by a surface tension gradient is one of the most important effects on producing materials in space, for example, a thermocapillary oscillatory convection may result in striations or segregation bands in crystal growth of semiconductors (Walter, 1987).. In order to explore the effect of thermocapillary convection on solidification of eutectic alloys and Marangoni migration of $\mathrm{Bi}$ droplets in $\mathrm{Al}-\mathrm{Bi}$ monotectic alloys, $\mathrm{Al}-\mathrm{RE}$, $\mathrm{Al}-\mathrm{Al}_{3} \mathrm{Ni}$ eutectic alloys and $\mathrm{Al}-\mathrm{Bi}$ alloys were carried out successfully in space on board Chinese recoverable satellites in 1990 and 1996 by the present authors (Zhang, 1993 and 1997). They discovered that the thermocapillary convection may be one of the important factors for forming the radiant eutectic structures under Microgravity conditions and they also analysed the Marangoni migration of Bi droplets in $\mathrm{Al}$ melt in space. Ratke et al (Ratke, 1996) considered that the microstructure of monotectic alloys results from the interaction among nucleation, growth, Stokes motion, Marangoni migration and the flow field, in which the Marangoni migration of the melted drop is important. The investigation of the effect of surface tension on solidification is the overlapping problem of materials science and fluid dynamics, which promotes the development of solidification theory and is useful for directing and improving the materials producing technique on the ground.

\section{EXPERIMENT PROCEDURE}

$\mathrm{Al}-10 \% \mathrm{Bi}$ immiscible alloys with homogenous structure were manufactured by control casting technique. A sample of $\mathrm{Al}-\mathrm{Bi}+\mathrm{Al}$ was prepared by diffusion welding. And $\mathrm{Al}_{-}-\mathrm{Al}_{3} \mathrm{Ni}$ eutectic alloys were prepared in a vacuum unidirectional furnace on the ground Lab. Solidification experiments with a temperature gradient furnace under microgravity conditions in space were performed on board a Chinese recoverable satellite in which the microgravity level is superior to $10^{-5} \mathrm{~g}_{0}$. The size of the samples were $8 \mathrm{~mm}$ in diameter, $8 \mathrm{~mm}$ in length for $\mathrm{Al}-\mathrm{Bi}$ and $\mathrm{Al}, 12 \mathrm{~mm}$ in length for $\mathrm{Al}-\mathrm{Al}_{3} \mathrm{Ni}$. The samples were placed into graphite crucibles and 
sealed in quartz tube in vacuum of $10^{-3} \mathrm{~Pa}$. Figure $1(\mathrm{a})$ and (b) show the temperature-time curve in space and the position of thermocouple on ampoule
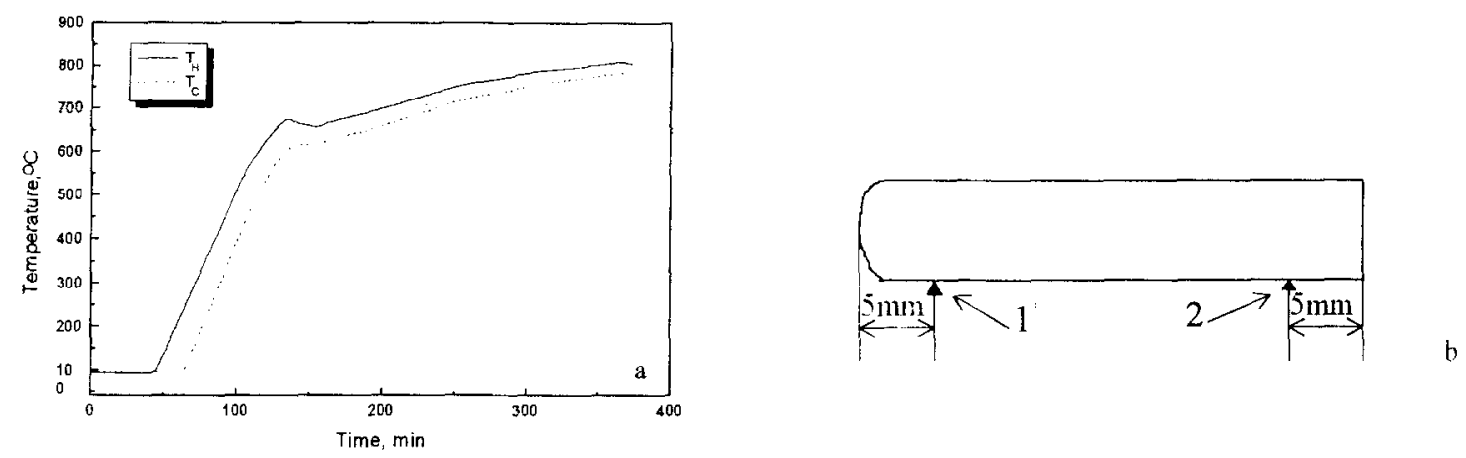

Fig. 1 Temperature-time curve in space (a) and position of thermocouple on ampoule (b) in gradient furnace in Chinese recoverable satellite.

\section{RESULTS AND DISCUSSION}

\section{Analysis of Radiant Eutectic Structure Obtained in Space}

A radiant structure of Al-RE eutectic alloy was found in a 1990 space experiment (Zhang, 1993). In this experiment, only the bottom of the sample partly wetted and adhered to the graphite crucible, which means the other part of the space melt would not contact with the crucible. The difference thermal transport at the bottom and the other surface will yield a temperature gradient which might cause surface tension gradient driven convection (Marangoni or thermocapillary convection) in the Al-RE melt. This convection may induce the radiant structure. In order to ensure the analysis, re-melt and solidification of $\mathrm{Al}_{-} \mathrm{Al}_{3} \mathrm{Ni}$ eutectic alloys were carried out in a space furnace with average temperature gradient of $5{ }^{\circ} \mathrm{C} / \mathrm{cm}$ in the 1996 recoverable satellite. No any radiant structure was found in one of the $\mathrm{Al}-\mathrm{Al}{ }_{3} \mathrm{Ni}$ eutectic sample $\left(1^{*}\right)$ with serious oxide surface, even the shape of the sample looks like a bullet with a bulboid head caused by surface tension effect, as shown in Figure 2(a) and (b). In another sample of $\mathrm{Al}-\mathrm{Al}{ }_{3} \mathrm{Ni}$ alloy $\left(2^{H}\right)$ with metallic luster surface, a more obvious radiant structure with double vortices of $\mathrm{Al}_{-} \mathrm{Al}_{3} \mathrm{Ni}$ eutectic was obtained as shown in Figure 3(a). For analyzing this phenomenon, the flow structure driven by surface tension in the melt was performed by using numerical calculation to solve basic equations of stream and vorticity functions with the thermophysical parameters of the alloys and the experiment data in space. The model adopted in the
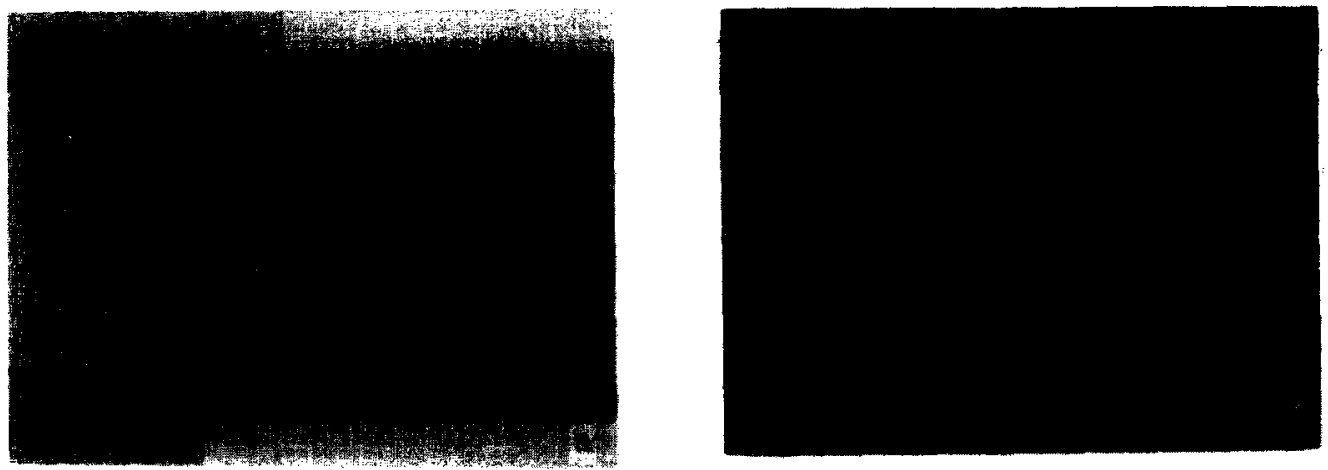

Fig. 2 Macrograph (a) and microstructure of $\mathrm{Al}-\mathrm{Al}_{3} \mathrm{Ni}\left(1^{\#}\right)$ in longitudinal section (b) on board Chinese recoverable satellite. 

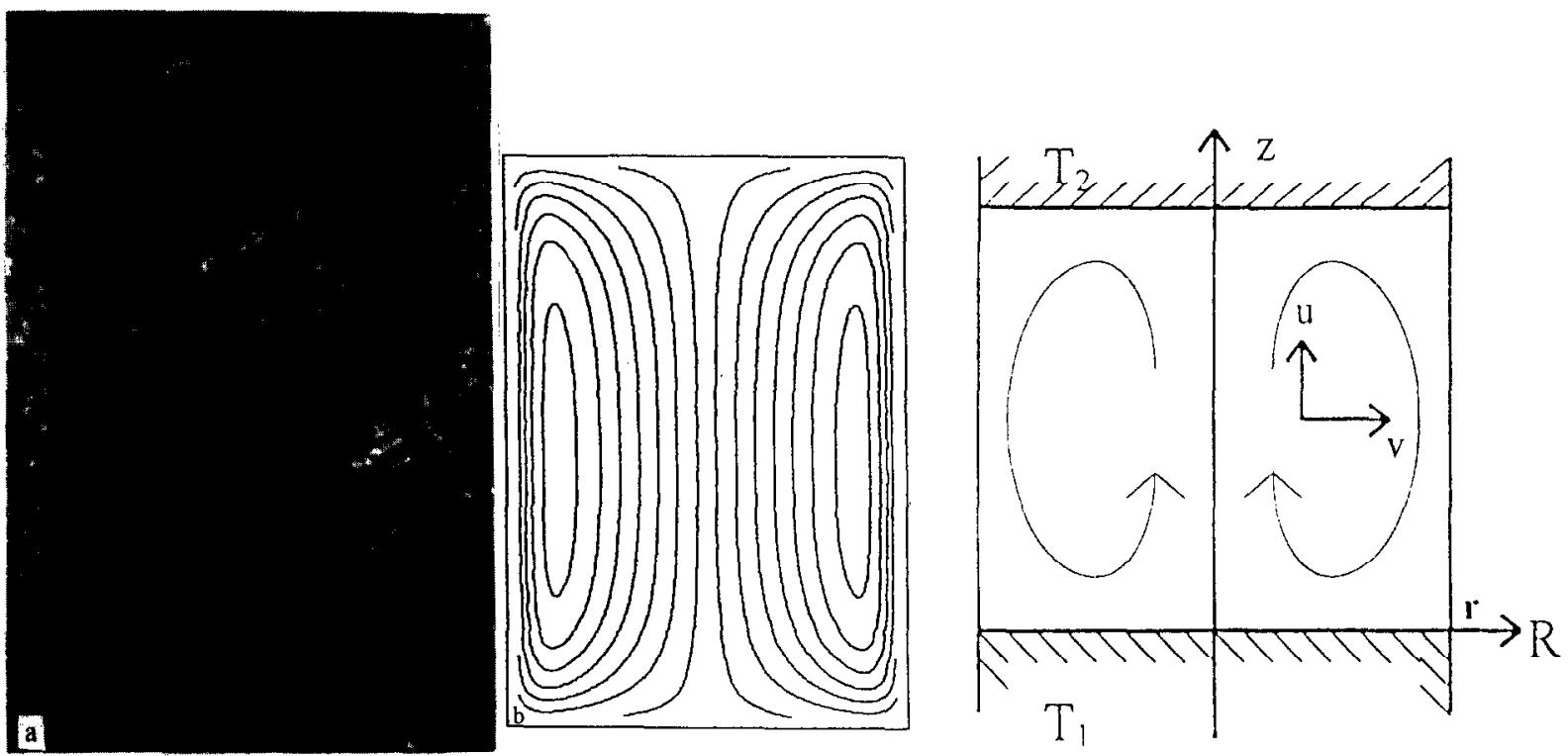

Fig. 3 Radiant eutectic structure with double vortices of $\mathrm{Al}-\mathrm{Al}_{3} \mathrm{Ni}$ alloy $\left(2^{\#}\right)$ obtained in space (a) and simulated thermocapillary convection pattern in the melt (b).

Fig.4 Schematic drawing of convection by surface tension gradient

present paper is shown in Figure 4. The melt is limited in a smooth cylindrical container, not pasted on the side cylindrical wall of the crucible, that is, it is can slide along the side cylindrical wall. The temperature $T_{2}$ at the top of the cylinder is higher than $T_{1}$ at the bottom. The non-uniform distribution of temperature at cylindrical wall drives convection along the direction shown in Figure 4, when the applied temperature difference $\Delta \mathrm{T}=\mathrm{T}_{2}-\mathrm{T}_{1}$ is lower than the critical one, the three-dimensional, steady and axis-symmetric flow field and temperature distribution satisfy the following non-dimensional equations:

$$
\begin{aligned}
& \frac{\partial \vec{U}}{\partial t}+(\vec{U} \cdot \nabla) \vec{U}=-\nabla(\Delta P)+\frac{1}{R_{e}} \nabla^{2} \vec{U} \\
& \frac{\partial T}{\partial t}+\vec{U} \cdot \nabla T=\frac{1}{M_{a}} \nabla^{2} T \\
& R_{e}=\frac{\left|\sigma_{T}\right| \Delta T L}{\rho v^{2}} \quad M_{a}=\frac{\left|\sigma_{T}\right| \Delta T L}{\rho v \kappa}
\end{aligned}
$$

with the following boundary conditions:

$\mathrm{v}=0, \frac{\partial u}{\partial r}+\frac{\partial I^{\prime}}{\partial z}=0, T_{r}=T_{1}+\left(T_{2}-T_{1}\right) z$

at the side cylindrical wall, and $\mathrm{v}=0, \mathrm{u}=0, \mathrm{~T}=\mathrm{T}_{1}$ at the bottom, $\mathrm{v}=0, \mathrm{u}=0, \mathrm{~T}=\mathrm{T}_{2}$ at the top, Where $\mathrm{u}$ and $\mathrm{v}$ are respectively the axial and radical components of the velocity vector $\vec{U}, \sigma_{\mathrm{T}}$ is the surface tension differentiation with respect to temperature, $\mathrm{L}$ represents the length of the melt region and $\rho, v, \kappa$ are the density, kinematics viscosity and the thermal diffusion coefficients respectively. Figure 3 (b) is the simulated flow pattern of thermocapillary convection in $\mathrm{Al}-\mathrm{Al}_{3} \mathrm{Ni}$ melt. The pattern is similar to the radiant eutectic structure. When the solid-liquid (s-l) interface pushes upward, the flow effect still exists and has an influence on the temperature and solute redistribution as well as the configuration of solid-liquid interface. Under the temperature gradient of $5^{0} \mathrm{C} / \mathrm{cm}$ of the space furnace, the planar growth condition ( $\mathrm{G} / \mathrm{R}>1.786$ $\times 10^{5} \mathrm{C}$ for $\mathrm{Al}-\mathrm{Al}_{3} \mathrm{Ni}$ alloy ) is not satisfied. According to the microstructure of Figure 3 (a), the convexity of the solid-liquid interface should be changed gradually during solidification and the smaller the pulling velocity, the more curved the solid-liquid interface (Xiong, 1993). Furthermore, the eutectic phases of Al$\mathrm{Al}_{3} \mathrm{Ni}$ alloy always directionally grow along a direction normal to the solid-liquid interface, so the formation of the radiant eutectic structure may related to the convex change of the $s-1$ interface during the 
solidification.

\section{Marangoni Migration of Bi Droplets in Al-Bi Melt in Space}

Marangoni migration of $\mathrm{Bi}$-droplets in $\mathrm{Al}-$-melt was studied by re-melting an $\mathrm{Al}-10 \% \mathrm{Bi}+\mathrm{Al}$ sample in the gradient furnace under microgravity conditions in space. It was found that $\mathrm{Bi}$-droplets moved in the temperature gradient of $5{ }^{\circ} \mathrm{C} / \mathrm{cm}$ towards the hotter side of the sample. Figure 5(a) and (b) show the distribution of smaller $\mathrm{Bi}$ particles in $\mathrm{Al}-\mathrm{Bi}$ region and larger $\mathrm{Bi}$ particles in $\mathrm{Al}$ region. Figure 5(c) shows the size distribution of particles with different diameters and the area content as a function of axial positions.

The Marangoni migration velocity $V_{m}$ of droplets with mean diameter $r$ in a constant temperature gradient can be given by the equation of Young, Goldstein and Block (Young, 1959):

$V_{m}=\frac{2 \frac{d T}{d x} \frac{d \sigma_{L 1 L 2}}{d T} k}{\left(2 k+k^{\prime}\right)\left(2 \eta+3 \eta^{\prime}\right)} r$

Where $\eta, \eta{ }^{\prime} \kappa, \kappa$ ' are the viscosity and the thermal conductivity of the matrix liquid and the dispersion liquid, respectively. During solidification, the pushing velocity of s-1 interface is an important factor, which influence the particle distribution. The pushing velocity of s-l interface under microgravity can be given as follows(Neumann and Goldstein, 1959):

$V_{s}=\frac{2 a \Delta \sigma_{0} r^{2}}{3 \eta(r+d)^{2}(2 r+d)}$

Where $a$ is the atomic diameter, $d$ is the distance between droplets and interface. $\Delta \sigma_{0}$ is the difference of the interface energy. The calculations of Marangoni migration velocities $V_{m}$ and $V_{M}$ of mean diameter particles and maximum diameter particles, and pushing velocity Vs of the s-1 interface (in figure 5 (d)) show that the smaller $\mathrm{Bi}$ droplets were engulfed by the developing s-l interface and dispersed homogeneously in the $\mathrm{Al}-\mathrm{Bi}$ matrix. The larger $\mathrm{Bi}$ droplets of which migration velocity $\mathrm{V}_{\mathrm{m}}$ is larger than $\mathrm{V}_{\mathrm{s}}$ moved under the temperature gradient ahead of the s-l interface and distributed into $\mathrm{Al}$ matrix.
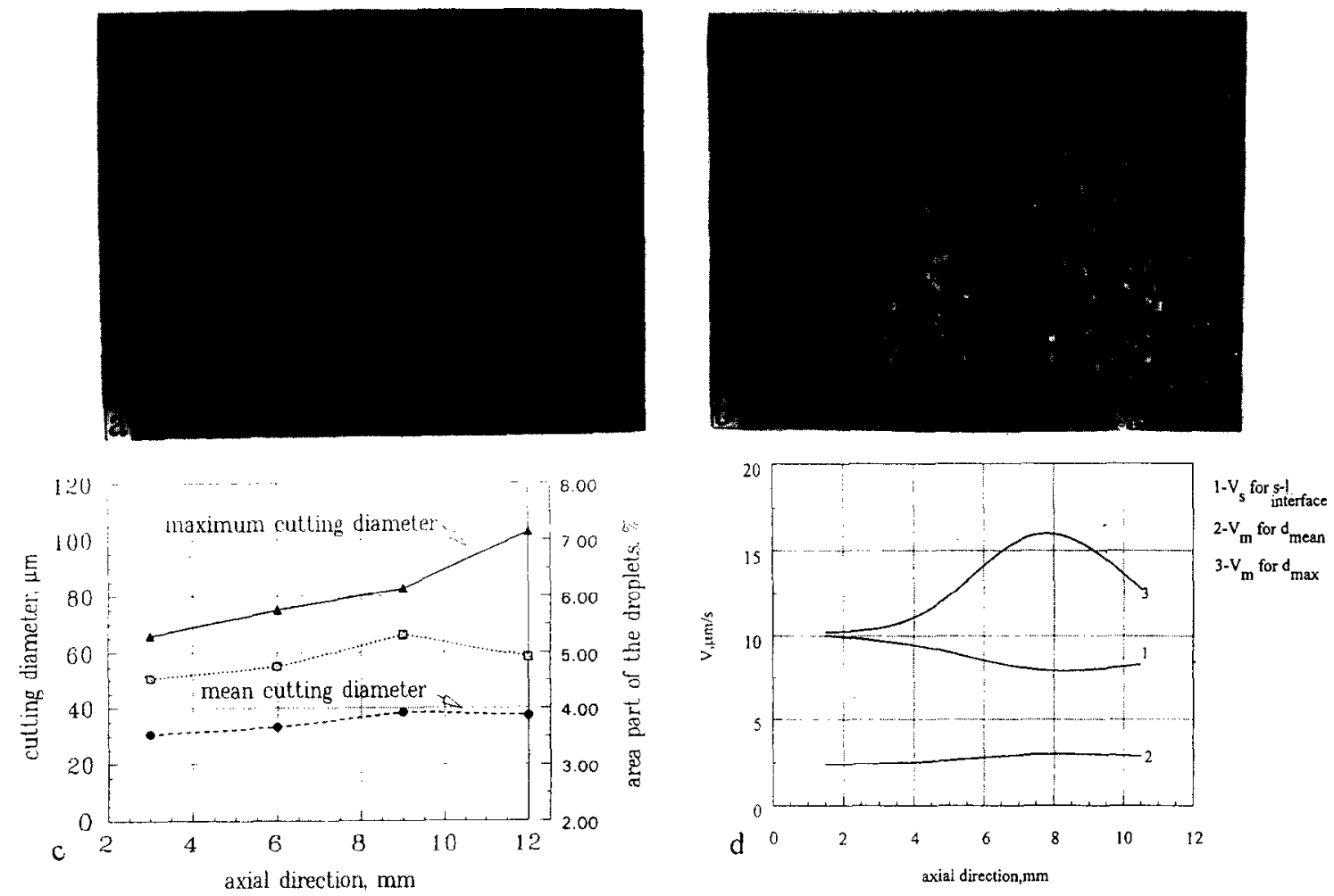

Fig. 5 Distribution of $\mathrm{Bi}$-particles in $\mathrm{Al}-\mathrm{Bi}$ region (a) and in $\mathrm{Al}$ region (b) obtained in space, particle size distribution (c). Migration and pushing velocities of $V_{m}, V_{M}$ and $V_{s}$ (d). 


\section{Application of Surface Tension Effect on Earth Solidification Process}

As a result of microgravity investigation in space, the droplets of the second phase in the melt of immiscible alloys can be moved towards hotter melt by Marangoni migration, which can be used to overcome the gravity effects on earth materials processing. In the technique, the net velocity of the droplets will be dependent on its size. When the resultant velocity is zero, there will be a critical size of the droplets. By controlling the stability of the solidification process, an ingot with uniform distribution of the droplets can be obtained as the microstructure of $\mathrm{Al}-10 \mathrm{~Pb} \%$ alloy shown in Fig. 6(a), (b) and (c). The critical size $r_{0}$ of the secondary phase droplets can be estimated by the following equation (Xian, 1996):

$$
r_{0}=\frac{3 \eta\left|\frac{d T}{d x}\right|\left|\frac{d \sigma_{L 1 L 2}}{d T}\right| \kappa}{g\left(2 \kappa+\kappa^{\prime}\right)\left(\rho-\rho^{\prime}\right)\left(\eta+\eta^{\prime}\right)}
$$

Solidification test on $\mathrm{Al}-\mathrm{Bi}, \mathrm{Al}-\mathrm{Pb}$ and $\mathrm{Al}-\mathrm{Pb}-\mathrm{Si}$ alloys showed that the size of the $\mathrm{Bi}$ and $\mathrm{Pb}$ particles in $\mathrm{Al}$ matrix is roughly the same order of magnitude as that obtained by above equation.

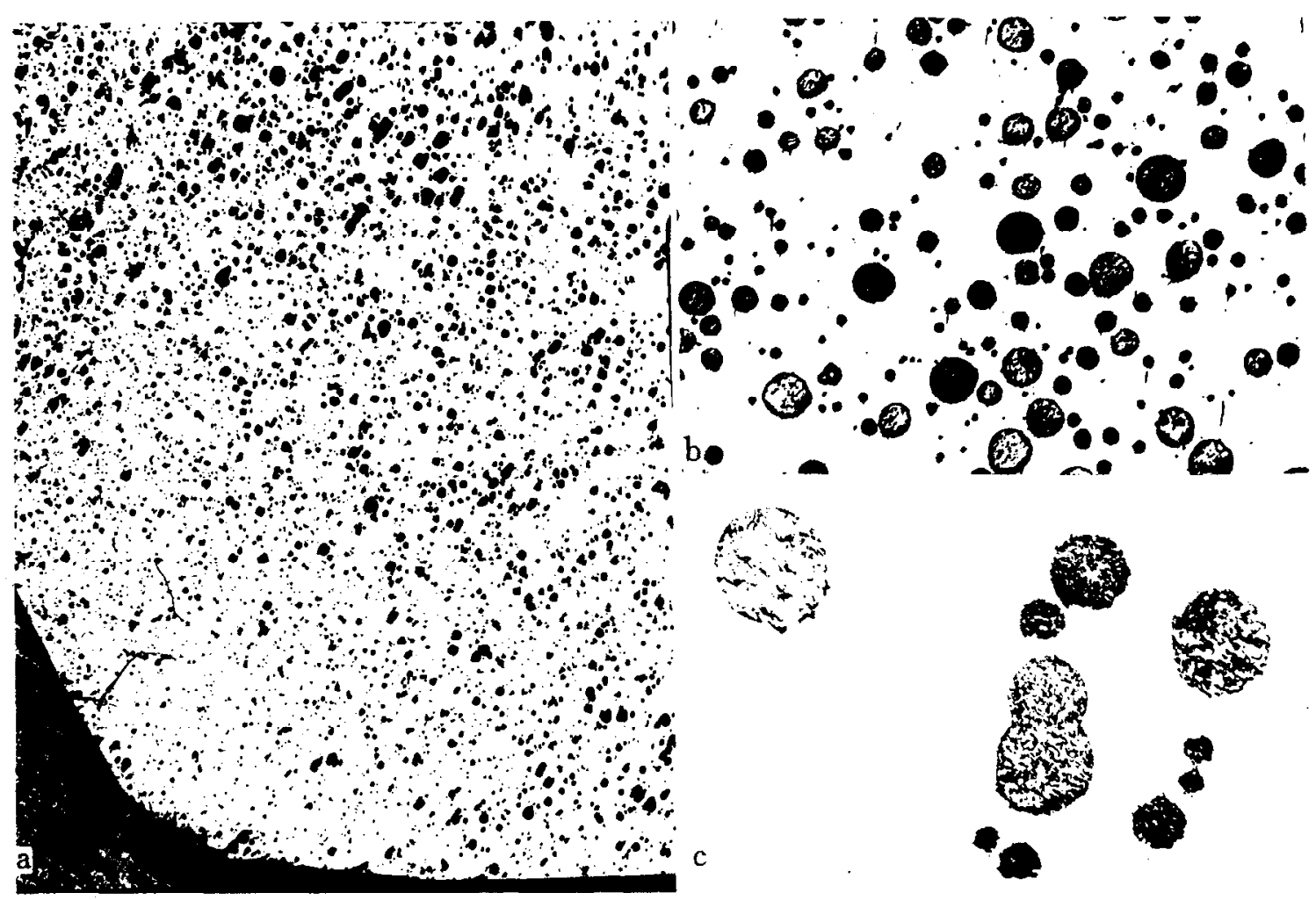

Fig. 6 Microstructure of the ingot of Al-10Pb alloy. (a) $12.8 \times \quad$ (b) $100 \times \quad$ (c) $400 \times$

\section{REFERENCE}

Neumann H. and CH.Kuhtz, Materials Science Forum 215-216, 277(1996)

Ratke L. et al, Proc. of China-Germany Workshop on Microgravity Sci., Xi'an, China, 1996, pp.73

Walter H. U.: Fluid Sciences and Materials Sciences in Space, ESA, 1987

Xian A. P., X. M. Zhang, Z. Y. Li, Q. Q. Liu, J. Z. Chen and Y. Y. Li: Acta Metallurgica Sinica, 32, 113-119 (1996)

Xiong B., Z. M. Tang and W. R. Hu, Microgravity Sci. Technol. VI/2, 131(1993)

Young N. O., J. S. Goldstein and M. J. Block, J. Fluid Mech., 6, 350 (1959)

Zhang X. M. et al: Microgravity Q., 3, 177 (1993)

Zhang X. M. et al: Proceedings of Third China Microgravity Sci., Lu Shan; China, Aug. 1997 pp.41 